\title{
Evaluation of $p$-phenylene-bis and phenyl dithiocarbamate sodium salts as inhibitors of mushroom tyrosinase
}

\author{
Ehsan Amin ${ }^{1}$, Ali Akbar Saboury ${ }^{1}{ }^{\boxplus}$, Hassan Mansouri-Torshizi2 ${ }^{2}$, Samane Zolghadri ${ }^{1}$ \\ and Abdol-Khalegh Bordbar ${ }^{3}$ \\ IInstitute of Biochemistry and Biophysics, University of Tehran, Tehran, Iran; ${ }^{2}$ Department of Chemistry, University of Sistan \& Bluchestan, \\ Zahedan, Iran; ${ }^{3}$ Department of Chemistry, University of Isfahan, Isfahan, Iran
}

Two structurally related compounds, phenyl dithiocarbamate sodium salt (I) and $p$-phenylene-bis (dithiocarbamate) sodium salt (II) were prepared by reaction of the parent aniline and $p$-phenylenediamine with $\mathrm{CS}_{2}$ in the presence of sodium hydroxide. These water soluble compounds were characterized by spectroscopic techniques, IR, ' $\mathrm{H}$ NMR and elemental analysis. The inhibitory effects of both compounds on both activities of mushroom tyrosinase (MT) from Agricus bisporus were studied at two temperatures, $27^{\circ} \mathrm{C}$ and $37^{\circ} \mathrm{C}$. L-3, 4-dihydroxyphenylalanine (L-DOPA), and L-tyrosine were used as natural substrates for the catecholase and cresolase enzyme reactions, respectively. Kinetic analysis confirmed noncompetitive inhibition mode of I and mixed type of II on both activities of MT; I and II inhibit MT with inhibition constants $\left(K_{1}\right)$ of $300 \mu \mathrm{M}$ and $4 \mu \mathrm{M}$, respectively. Analysis of thermodynamic parameters indicated predominant involvement of hydrophobic interactions in binding of I and electrostatic ones in binding of II to MT. It seems that II is a more potent MT inhibitor due to its two charged head groups able to chelate copper ions in the enzyme active site. Intrinsic fluorescence studies as a function of concentrations of both compounds showed unexpectedly quenching of emission intensity without any shift of emission maximum. Extrinsic ANS-fluorescence indicated that only binding of I induces limited changes in the tertiary structure of MT, in agreement with the postulated hydrophobic nature of the binding mechanism.

Keywords: mushroom tyrosinase, $p$-phenylene-bis (dithiocarbamate), phenyl dithiocarbamate, noncompetitive inhibition, mixed inhibition, inhibition constant

Received: 19 August, 2010; revised: 09 June, 2010; accepted: 08 July, 2010; available on-line: 19 August, 2010

\section{INTRODUCTION}

Tyrosinase (polyphenol oxidase EC 1.14.18.1) is a copper-containing enzyme (Matoba et al., 2006) involved in pigment biosynthesis of various organisms. Mushroom tyrosinase (MT) from Agaricus bisporus due to its accessibility is well characterized and has been used in enzymatic studies (Nakamura et al., 1966; Jolley \& Nelson, 1969). It has been proposed that MT consists of two subunits, a heavy $(\mathrm{H})$ and a light $(\mathrm{L})$ with molecular mass of $43 \mathrm{kDa}$ and $13.4 \mathrm{kDa}$, respectively. In aqueous solution the predominant form of MT has the quaternary structure $(\mathrm{HL})_{2}$ with an estimated molecular mass of $120 \mathrm{kDa}$ (Strothkamp et al., 1976). The active site of tyrosinase consists of two closely spaced copper ions each coordinated by three histidine residues (Decker et al., 2006). The two $\mathrm{Cu}(\mathrm{II})$ ions are coupled antiferromagnetically (Holm et al., 1996). This copper pair is the site of interaction of tyrosinase with both molecular oxygen and its organic substrates. In this active site, monooxygenation of monophenoles to diphenoles (cresolase activity) and oxidation of diphenoles to o-quinones (catecholase activity) are catalyzed (Fenoll et al., 2001).

In fruits, fungi and vegetables the melanins are responsible for the formation of melanins leading to browning of wounded tissue exposed to air and the browning occurring during post-harvest storage (Fraignier et al., 1995; Garcia-Molina et al., 2005; Halaouli et al., 2006). In agriculture, browning poses a significant problem of huge economical impact (Artes et al., 1998; Seo et al., 2003; Bittner, 2006). The accumulation of an abnormal melanin amount in different specific parts of the skin, resulting in more pigmented patches, is also an esthetic problem. Tyrosinase inhibition is the most common approach to achieve skin depigmentation (Briganti et al., 2003; Parvez et al., 2006). Therefore, identification of compounds that inhibit melanin formation is extremely important. A considerable number of tyrosinase inhibitors are known (Kim \& Uyama, 2005). Synthetic tyrosinase inhibitors may be used as drugs and chemicals (captopril and methimazole) (Espin \& Wichers, 2001). Much effort has been put into searching for effective tyrosinase inhibitors because of their broad applications. In the last decades, thiol compounds have been extensively investigated as tyrosinase inhibitors, amoung them alkylidenethiosemicarbazide, $n$-alkyl xanthates, n-alkyl dithiocarbamates, $N$-aryl $S$-alkylthiocarbamate, phenylthiourea, and tetrathiotungstate (Gheibi et al., 2005; Lee et al., 2005; Park et al., 2006; Alijanianzadeh \& Saboury, 2007; Alijanianzadeh et al., 2007; Criton \& Mellay-Hamon, 2008; Liu et al., 2009).

Dithiocarbamates are organosulfur compounds of robust synthetic and chemical properties (Siddiqi et al., 2007) and are produced in great quantities (Vaneet et al., 2005; Khwaja et al., 2006). Their insecticidal, herbicidal, and fungicidal properties, have a wide range of applications. Because of their high biological activity, dithiocarbamates are also used in medicine, the rubber industry, and in the treatment of chronic alcoholism (Givseppina et al., 2005). The chemical properties of dithiocar-

e-mail: saboury@ut.ac.ir

Abbreviations: ANS, 1-anilinonaphthalene-8-sulfonate; L-DOPA, 4-dihydroxyphenylalanine; MT, mushroom tyrosinase 
bamates are due to the presence of one or more active -NCSS- group in their structures. This functional group can form complexes with almost all elements, including metal atoms of metal-containing enzymes, thus blocking their catalytic activity (Sanchez-Cortes et al., 1998). More recently, our group has studied the inhibitory effects of some synthetic thiocarbamates on mushroom tyrosinase activities (Gheibi et al., 2005; Saboury et al., 2006; 2007; Alijanianzadeh \& Saboury, 2007; Alijanianzadeh et al., 2007; Amin et al., 2009). In the present investigation, a kinetic analysis is presented of the inhibition of both cresolase and catecholase activities by $p$-phenylene-bis and phenyl dithiocarbamate sodium salts (Fig. 1) at two temperatures.

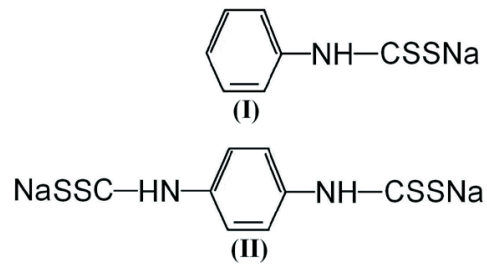

Figure 1. Structure of phenyl dithiocarbamate sodium salt (I) and $p$-phenylene-bis (dithiocarbamate) sodium salt (II)

\section{MATERIALS AND METHODS}

Materials. Mushroom tyrosinase (MT; EC 1.14.18.1; specific activity 5370 units/mg), L-3, 4-dihydroxyphenylalanine (L-DOPA), L-tyrosine and 1-anilinonaphthalene-8-sulfonate (ANS) were purchased from Sigma. $\mathrm{CS}_{2}, \mathrm{NaOH}$, aniline and $p$-phenylenediamine were used as supplied (Aldrich products). The solvents used were purchased from Merck Chemical Company. Phosphate buffer $(50 \mathrm{mM}, \mathrm{pH}$ 6.8) was used throughout this work. All buffers were prepared with water purified by a Milli Q water purification system.

Methods. Infrared spectra in $\mathrm{KBr}$ pellets were recorded on a Nicolet 5-DXB FT-IR spectrophotometer in the rang of $4000-400 \mathrm{~cm}^{-1}$. ${ }^{1} \mathrm{H}$ NMR spectra in DMSO- $\mathrm{d}_{6}$ were recorded on a Brucker DRX-500 Avance spectrophotometer at $500 \mathrm{MHz}$ using sodium-3-trimethylpropionate as the internal reference. ${ }^{1} \mathrm{H}$ NMR data are expressed in parts per million (ppm) and are reported as chemical shift position $(\delta \mathrm{H})$, multiplicity ( $\mathrm{s}=$ singlet, $\mathrm{d}$ $=$ doublet, $\mathrm{t}=$ triplet, $\mathrm{q}=$ quartet, $\mathrm{m}=$ multiplet, $\mathrm{sb}$ $=$ singlet broad) and assignment. Melting points were measured on a unimelt capillary melting point apparatus and are reported uncorrected. Microchemical analysis of carbon, hydrogen and nitrogen were carried out on CHN Rapid Heraeus.

Synthesis of phenyl dithiocarbamate sodium salt, NaSSC-HN-C $\mathbf{H}_{5}(\mathbf{I})$. This compound was prepared by a modified literature method (Desai et al., 2006; Manav et al., 2006). Aniline (4.55 mL, $50 \mathrm{mmol})$ solved in acetone $(40 \mathrm{~mL})$ and sodium hydroxide $(2 \mathrm{~g}, 50 \mathrm{mmol})$ solved in double distilled water $(20 \mathrm{~mL})$ were mixed and stirred vigorously in an ice bath. $\mathrm{CS}_{2}(10 \mathrm{~mL}$, excess) was added dropwise. Stirring continued for one hour in an ice bath and another three hours at room temperature. The mixture was then filtered, the volume of filtrate was reduced on a Rota evaporator to complete dryness and washed with acetone.

This crude product was recrystallized by dissolving in $50 \mathrm{~mL}$ acetone and filtering the undissolved particles out. Dichloromethane $(50 \mathrm{~mL})$ was added to the filtrate and placed in a refrigerator overnight. The desired product
I (yield $8.20 \mathrm{~g}, 85 \%$ ) was collected by filtration as white crystalline powder and washed with a small amount of dichloromethane and vacuum dried. Analysis (calculated for $\mathrm{C}_{7} \mathrm{H}_{6} \mathrm{NS}_{2} \mathrm{Na}$ ): C, 43.98; $\mathrm{H}, 3.14 ; \mathrm{N}, 7.33 \%$, found: $\mathrm{C}$, 43.97; H, 3.15; N, 7.31\%. Solid-state IR spectroscopy of I showed two characteristic bands at $1480 \mathrm{~cm}^{-1}$ and 969 $\mathrm{cm}^{-1}$ assigned to $v(\mathrm{~N}-\mathrm{CSS})$ and $\mathrm{v}(\mathrm{SCS})$ modes, respectively.(Givseppina et al., 2005). ${ }^{1} \mathrm{H}$ NMR (500 MHz, DMSO$\mathrm{d}_{6}$, ppm): 6.88 (m, a para $\left.=\mathrm{CH}-\right), 7.14$ (m, two meta $=$ $\mathrm{CH}-), 7.86$ (m, two ortho $=\mathrm{CH}-), 10.01(\mathrm{sb},-\mathrm{NH}-)$.

Synthesis of $p$-phenylene-bis (dithiocarbamate) sodium salt, NaSSC-NH- $\mathrm{C}_{6} \mathrm{H}_{4}-\mathrm{NH}-\mathrm{CSSNa}$ (II). The same procedure as for (I) was applied. To a solution of $p$-phenylenediamine $(5.41 \mathrm{~g}, 50 \mathrm{mmol})$ in acetone $(40 \mathrm{~mL})$ was added $40 \mathrm{~mL}$ of aqueous solution of sodium hydroxide (4 g, $100 \mathrm{mmol})$, and the mixture was stirred and cooled to $0^{\circ} \mathrm{C}$. To the cold mixture $10 \mathrm{~mL}$ (excess) of $\mathrm{CS}_{2}$ was added dropwise under vigorous stirring. The yellow solution so obtained was stirred for $2 \mathrm{~h}$ at $0^{\circ} \mathrm{C}$ and $12 \mathrm{~h}$ at room temp. It was then filtered and the filtrate evaporated under reduced pressure nearly to dryness. Over the yellow viscous liquid so obtained 30 $\mathrm{mL}$ of acetone was poured and the mixture stirred until the product of reaction solidified into the yellow powder. It was filtered and dissolved in $40 \mathrm{~mL}$ of water and filtered again. Acetone $(80 \mathrm{~mL})$ was added to the filtrate and left in a refrigerator overnight. The desired product was collected by filtration as white crystals, washed with acetone and vacuum dried. Yield was $12.92 \mathrm{~g}(85 \%)$. Analysis (calculated for $\mathrm{C}_{8} \mathrm{H}_{6} \mathrm{~N}_{2} \mathrm{~S}_{4} \mathrm{Na}_{2}$ ): C, 31.58; $\mathrm{H}, 1.97$; N, 9.21\% found C, 31.56; H, 1.96; N, 9.22\%. Solid-state IR spectroscopy of II showed two characteristic bands at 1494 and $971 \mathrm{~cm}^{-1}$ assigned to $v(\mathrm{~N}-\mathrm{CSS})$ and $v(\mathrm{SCS})$ modes, respectively (Givseppina et al., 2005). ${ }^{1} \mathrm{H}$ NMR (500 MHz, DMSO-d $\left.{ }_{6}, \mathrm{ppm}\right): 7.61$ (s, $\left.-\mathrm{C}_{6} \mathrm{H}_{4}-\right), 9.83$ (sb, -NH-).

Kinetic measurements. Kinetic assays of mushroom tyrosinase were determined by measuring spectrophotometrically at $475 \mathrm{~nm}\left(\mathrm{~A}_{475}\right.$ the amount of dopachrome formed in the reaction mixture using a Cary spectrophotometer 100 Biomodel, with jacketed cell holders) (GarcíaMolina et al., 2007). First the enzyme dissolved in one milliliter of $50 \mathrm{mM}$ phosphate buffer ( $\mathrm{pH}$ 6.8) was incubated with different concentrations of each inhibitor. Then, the substrate was added to the reaction mixture and the reaction was monitored for $2 \mathrm{~min}$. The final concentration of MT was $26.07 \mu \mathrm{g} / \mathrm{mL}$ for the cresolase activity and 6.52 $\mu \mathrm{g} / \mathrm{mL}$ for the catecholase activity. The measurement was performed in triplicate for each experiment and averaged before further calculation. The inhibitory effects of both compounds were determined at two temperatures: $27^{\circ} \mathrm{C}$ and $37^{\circ} \mathrm{C}$. For estimation of the type of inhibition and obtain $K_{\mathrm{I}}$ values, the experimental results were analysed by Lineweaver-Burk plots.

Intrinsic and ANS-binding fluorescence experiments. The fluorescence emission spectra were measured with a Hitachi spectrofluorimeter, MPF-4 model, equipped with a thermostatically controlled cuvette compartment. The tryptophan fluorescence was excited at $280 \mathrm{~nm}$. The changes of the extrinsic fluorescence intensity were studied by labeling MT with ANS, at the molar concentration ratio of

$\frac{C_{\text {ANS }}}{C_{\text {Enzyme }}}=50$

for 10 min prior to measurement (Gasymov \& Glasgow, 2007). The fluorescence of bound ANS was excited at $390 \mathrm{~nm}$. 


\section{RESULTS AND DISCUSSION}

For evaluating the inhibitory activity of the two compounds (I and II) tyrosinase inhibition assays were performed using L-tyrosine and L-DOPA as cresolase and catecholase substrates of the enzyme, respectively. In order to obtain thermodynamic parameters, the experiments were carried out at two temperatures: $27^{\circ} \mathrm{C}$ and $37^{\circ} \mathrm{C}$.

\section{Inhibitory effects of I on MT activities}

In the cresolase activity assay, after about $15 \mathrm{~s}$ (lag time) the curve of absorbance $\left(\mathrm{A}_{475}\right)$ versus time rose nearly linearly, with a constant slope, referred to as the initial steady state rate. In the catecholase activity assay the steady state rate was reached without a lag time. The steady state rate of the two activities decreased with increasing concentration of compound I. The LineweaverBurk equation, which can be used to determine the type of inhibition, is:

$\frac{1}{V}=\frac{K_{m}^{\prime}}{V_{\max }^{\prime}} \frac{1}{S^{\prime}}+\frac{1}{V_{\max }^{\prime}}$

where $V$ and $V_{\text {max }}^{\prime}$ are the initial and maximum velocities, respectively, and $K_{m}^{\prime}$ is the Michaelis-Menten constant in the presence of an inhibitor. The LineweaverBurk plots of $1 / V$ vs. $1 /[S]$ in the presence and absence of an inhibitor may be used to determine the type of inhibition (Saboury, 2009). These plots in the absence and presence of a noncompetitive inhibitor at different fixed concentrations intersect each other on the $\mathrm{X}$-axis, which means that the inhibitor does not change the $K_{m}^{\prime}$ while $V^{\prime}$ is gradually decreased (Figs. 2-5). The type of the slope and/or vertical intercept (Y-int) dependence on the inhibitor concentration can also be used to determine the inhibition constant $\left(K_{\mathrm{I}}\right)$ according to a plot named the secondary plot (insets in Figs. 2-5):

$Y-$ int $=\frac{1}{V_{\max }}\left(1+\frac{[I]}{K_{I}}\right)$

So, considering Lineweaver-Burk plots at different concentrations of $\mathbf{I}$, shown in Figs. 2-5, we can conclude that in both temperatures compound I inhibits MT noncompetitively. Also, inhibition constants of I were calculated from the insets in figures and summarized in Table 1. The understanding of molecular recognition processes of ligand binding to biological macromolecules requires complete characterization of the binding energetic. A quantitative description of the forces that govern molecular associations requires determination of changes of all thermodynamic parameters, including standard free energy $\left(\Delta G^{\circ}\right)$, enthalpy $\left(\Delta H^{\circ}\right)$, and entropy $\left(\Delta S^{\circ}\right)$ of binding (Perozzo et al., 2004). $\Delta G^{\circ}$ can be calculated from association constant as follows:

$\Delta G^{\mathrm{o}}=-R T \ln K_{\mathrm{a}}$

where $R$ is the gas constant and $T$ is the absolute temperature. Also, $\Delta H^{\circ}$ may be obtained from association constants $K_{\mathrm{a} 1}$ and $K_{\mathrm{a} 2}\left(K_{\mathrm{a}}=1 / K_{\mathrm{I}}\right)$ in two temperatures of $T_{1}$ and $T_{2}$, respectively, using van't Hoff equation:

$\ln \frac{K_{a 2}}{K_{a 1}}=-\frac{\Delta H^{\circ}}{R}\left(\frac{1}{T_{2}}-\frac{1}{T_{1}}\right)$

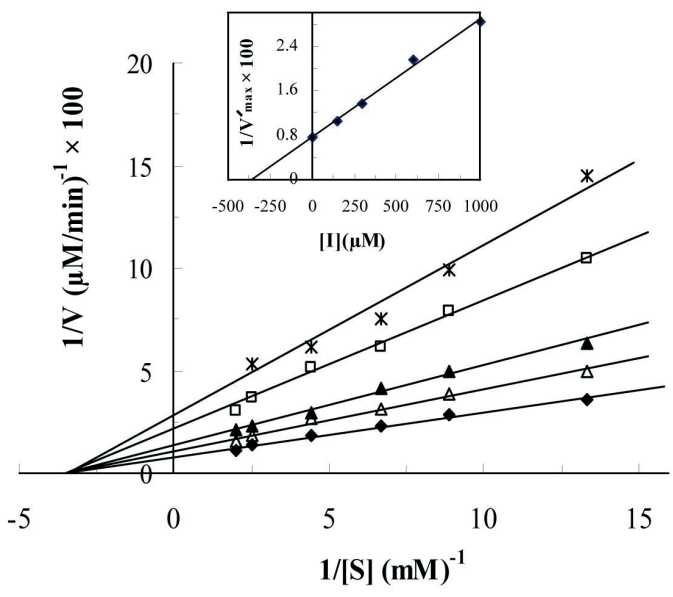

Figure 2. Lineweaver-Burk plots in the presence of fixed concentrations of I for cresolase reactions; Inset: $1 / V_{\max }$ versus inhibitor concentration [I]

L-Tyrosine was a substrate. The assay was done in $50 \mathrm{mM}$ sodium phosphate buffer, $\mathrm{pH} 6.8$, at $27^{\circ} \mathrm{C}$ and $26.07 \mu \mathrm{g} / \mathrm{mL}$ enzyme, in the presence of different concentrations of I: $0 \mu \mathrm{M}(\bullet), 150 \mu \mathrm{M}(\triangle)$, $300 \mu \mathrm{M}(\mathbf{\Delta}), 600 \mu \mathrm{M}(\square), 1000 \mu \mathrm{M}(*)$.

Finally, $\Delta S^{\circ}$ is directly calculated from $\Delta G^{\circ}$ and $\Delta H^{\circ}$ according to Eqn. 5:

$\Delta S^{\circ}=\frac{\left(\Delta H^{\mathrm{o}}-\Delta G^{\mathrm{o}}\right)}{T}$

All thermodynamic parameters of $\mathbf{I}$ binding are summarized in Table 1. In noncompetitive inhibition, both $\mathbf{I}$ and the substrate bind to different sites of the enzyme independently. The degree of inhibition is unaffected by changes in the substrate concentration. The negative $\Delta G^{\circ}$ value indicates spontaneous binding of I to MT. Also, the decrease of dissociation constant following with increase temperature indicates that binding is entropy driv-

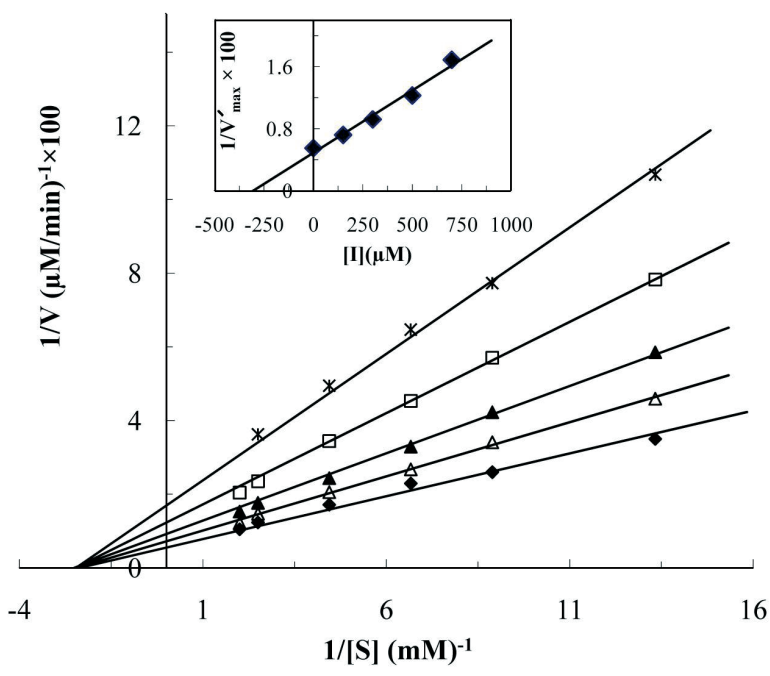

Figure 3. Lineweaver-Burk plots in the presence of fixed concentrations of I for cresolase reactions; Inset: $1 / V_{\max }$ versus inhibitor concentration [I]

L-tyrosine was a substrate. The assay was done in $50 \mathrm{mM}$ sodium phosphate buffer, $\mathrm{pH} 6.8$, at $37^{\circ} \mathrm{C}$ and $26.07 \mu \mathrm{g} / \mathrm{mL}$ enzyme, in the presence of different concentrations of I: $0 \mu \mathrm{M}(\bullet), 150 \mu \mathrm{M}$ $(\triangle), 300 \mu \mathrm{M}(\boldsymbol{\Delta}), 600 \mu \mathrm{M}(\square), 1000 \mu \mathrm{M}(*)$. 


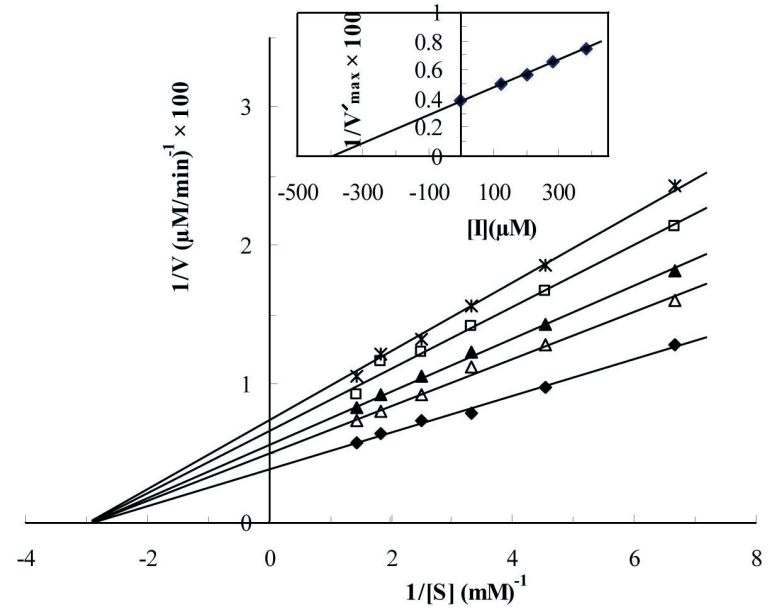

Figure 4. Lineweaver-Burk plots in the presence of fixed concentrations of I for catecholase activities; Inset: $1 / V_{\max }$ versus inhibitor concentration [I]

L-DOPA was a substrate. The assay was done in $50 \mathrm{mM}$ sodium phosphate buffer, $\mathrm{pH} 6.8$, at $27^{\circ} \mathrm{C}$ and $6.52 \mu \mathrm{g} / \mathrm{mL}$ enzyme, in the presence of different concentrations of I: $0 \mu \mathrm{M}(\diamond), 120 \mu \mathrm{M}(\triangle)$, $200 \mu \mathrm{M}(\mathbf{\Delta}), 280 \mu \mathrm{M}(\square), 380 \mu \mathrm{M}(*)$.

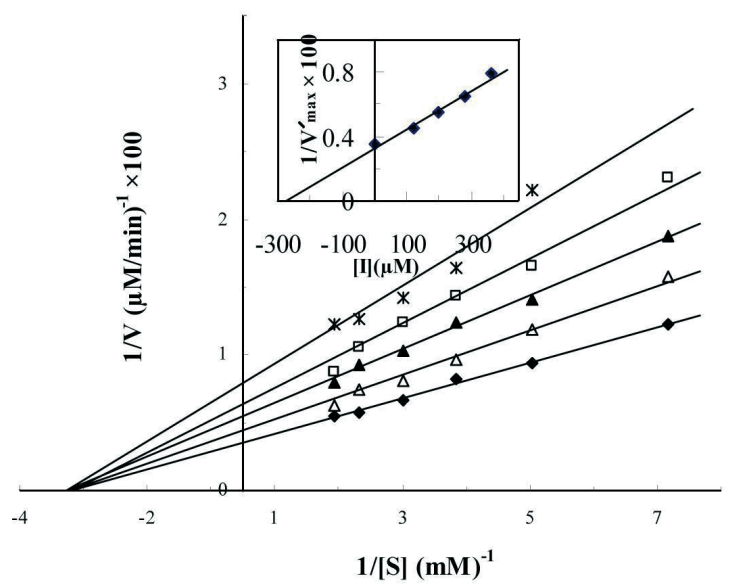

Figure 5. Lineweaver-Burk plots in the presence of fixed concentrations of I for catecholase activities; Inset: $1 / V_{\max }$ versus inhibitor concentration [I]

L-DOPA was a substrate. The assay was done in $50 \mathrm{mM}$ sodium phosphate buffer, $\mathrm{pH} 6.8$, at $37^{\circ} \mathrm{C}$ and $6.52 \mu \mathrm{g} / \mathrm{mL}$ enzyme, in the presence of different concentrations of I: $0 \mu \mathrm{M}(\bullet), 120 \mu \mathrm{M}(\triangle)$, $200 \mu \mathrm{M}(\mathbf{\Delta}), 280 \mu \mathrm{M}(\square), 380 \mu \mathrm{M}(*)$.

en and that hydrophobic forces are predominant ones in the mechanism of binding. On the other hand, many compounds containing sulfur atoms are known as metal ions chelating agents and competitive inhibitors of MT<smiles>NC(=S)Nc1ccccc1</smiles>

(a) (b)<smiles>CCN(CC)C([O-])=S</smiles>

Figure 6. (a) Phenylthiourea, (b) Diethyldithiocarbamate.

catalytic activity (Rescigno et al., 2002; Gheibi et al., 2005; Ronconi et al., 2005). Chelating of ions involves electrostatic forces. So, the hydrophobic tail of compound I (Fig. 1) it is likely to play a considerable role both in binding as well as in chelating by its dithiol head of a copper ion in the active site of MT. Furthermore, similar results were reported before. Diethyldithiocarbamate was shown to act as a competitive inhibitor while phenylthiourea as a noncompetitive one (Fig. 6) (Rescigno et al., 2002; Criton \& Mellay-Hamon, 2008). The greater entropy change accompanying catecholase activity than that of cresolase one show that hydrophobic interactions play a very important role in the catecholase activity.

\section{Inhibitory effects of II on MT activities}

In fixed concentrations of compound II and different concentration of each of the two substrates, initial steady state rates of enzymatic reactions were measured at two temperatures for both activities. The results thus obtained are shown in the form of Lineweaver-Burk plots in Figs. 7-10. The Lineweaver-Burk plots (Eqn. 1) in the absence and presence of a mixed type inhibitor at its different fixed concentrations may intersect each other above the negative $\mathrm{X}$-axis which means that both $K_{\mathrm{m}}$ and $V_{\max }$ change as a function of the concentration of this inhibitor type (Saboury, 2009). Also the slop and Y-int vary as follows:

$$
\begin{aligned}
& Y-\text { int }=\frac{1}{V_{\max }}\left(1+\frac{[I]}{\alpha K_{I}}\right) \\
& \text { Slope }=\frac{K_{m}}{V_{\max }}\left(1+\frac{[I]}{K_{I}}\right)
\end{aligned}
$$

where $\alpha$ is the interaction parameter for binding sites of substrate and inhibitor and $K_{\mathrm{I}}$ is the inhibition constant of equilibrium binding of inhibitor to the enzyme $(E)$. So, by plotting secondary plots (insets in Figs. 7-10) one can calculate $K_{\mathrm{I}}$ values (summarized in Table 2). Also, the inhibition constants in two temperatures were used to obtain thermodynamic parameters (Table 2). This results showed that compound II can bind not only to the free enzyme but also to the enzyme-substrate complex and thereby decreasing the affinity of the substrate. The increasing $K_{\mathrm{I}}$ values with increasing temperature indicates that the binding is enthalpy driven and consequently, involves predominantly electrostatic forces. Considering the chemical structure of compound II (Fig. 1) and the thermodynamics of its binding to MT it seems that II with two 


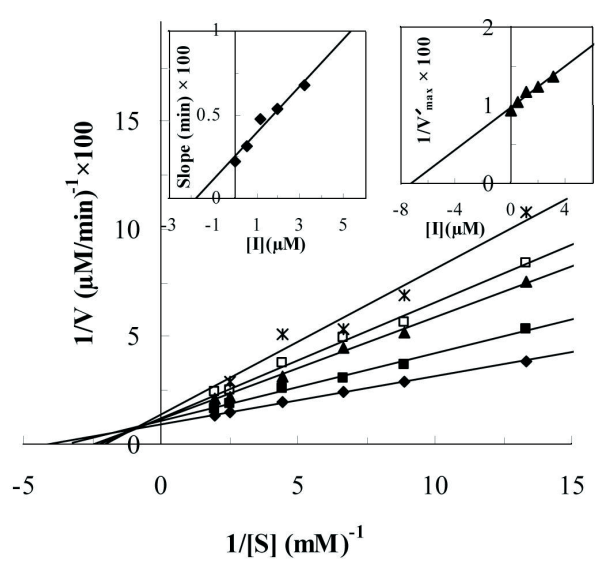

Figure 7. Lineweaver-Burk plots in the presence of fixed concentrations of II for cresolase activities; Insets: slope and $1 / V_{\max }$ of Lineweaver-Burk plots versus inhibitor concentrations [II] L-tyrosine was a substrate. The assay was done in $50 \mathrm{mM}$ sodium phosphate buffer, $\mathrm{pH} 6.8$, at $27^{\circ} \mathrm{C}$ and $26.07 \mu \mathrm{g} / \mathrm{mL}$ enzyme, in the presence of different concentrations of II: $0 \mu \mathrm{M}(\bullet), 0.6 \mu \mathrm{M}$ $(\bullet), 1.2 \mu \mathrm{M}(\boldsymbol{\Delta}), 2 \mu \mathrm{M}(\square), 3.2 \mu \mathrm{M}(*)$.

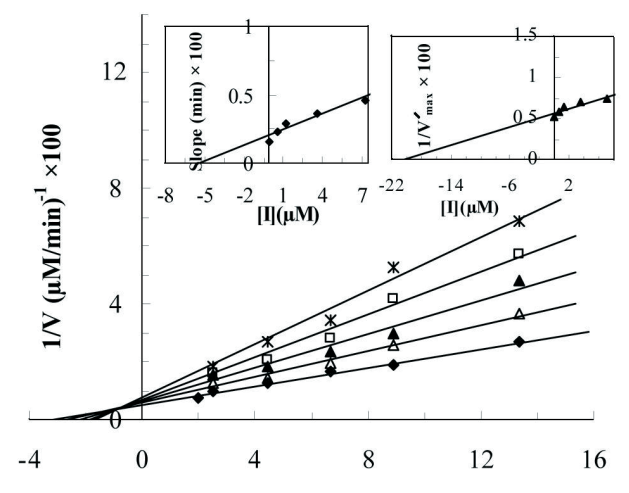

$1 /[\mathrm{S}](\mathrm{mM})^{-1}$

Figure 8. Lineweaver-Burk plots in the presence of fixed concentrations of II for cresolase activities; Insets: slope and $1 / V_{\max }$ of Lineweaver-Burk plots versus inhibitor concentrations [II]. L-tyrosine was a substrate. The assay was done in $50 \mathrm{mM}$ sodium phosphate buffer, $\mathrm{pH} 6.8$, at $37^{\circ} \mathrm{C}$ and $26.07 \mu \mathrm{g} / \mathrm{mL}$ enzyme, in the presence of different concentrations of II: $0 \mu \mathrm{M}(\bullet), 0.6 \mu \mathrm{M}$ $(\triangle), 1.2 \mu \mathrm{M}(\mathbf{\Delta}), 3.6 \mu \mathrm{M}(\square), 7.2 \mu \mathrm{M}(*)$.

negatively charged heads can chelate copper ions in the enzyme active site and thus affect the binding affinity of the substrate. Compound II is apparently a more potent inhibitor than $\mathbf{I}$, in agreement with the notion that electrostatic forces play a very important role in the inhibition of MT by thiol compounds.

Table 2. Inhibition and thermodynamic parameters of binding of $p$-phenylene-bis (dithiocarbamate) sodium salt (II) to MT

\begin{tabular}{llllllll}
\hline Reaction type & $\begin{array}{l}\text { Temperature } \\
\left({ }^{\circ} \mathrm{C}\right)\end{array}$ & $\begin{array}{l}K_{\mathrm{l}} \\
(\mu \mathrm{M})\end{array}$ & $\mathrm{a}$ & $\begin{array}{l}K_{\mathrm{a}} \\
\left(\mathrm{M}^{-1} \times 10^{5}\right)\end{array}$ & $\begin{array}{l}\Delta G^{\circ} \\
\left(\mathrm{KJ} \mathrm{mol}^{-1}\right)\end{array}$ & $\begin{array}{l}\Delta H^{\circ} \\
\left(\mathrm{kJ} \mathrm{mol} \mathrm{mol}^{-1}\right)\end{array}$ & $\begin{array}{l}T \Delta S^{\circ} \\
\left(\mathrm{kJ} \mathrm{mol} \mathrm{mol}^{-1}\right)\end{array}$ \\
\hline Cresolase & 27 & 1.8 & 4.2 & 5.56 & -33 & -85 & -52 \\
& 37 & 5.3 & 3.9 & 1.89 & -31 & & -42 \\
Catecholase & 27 & 1.7 & 4.6 & 5.88 & -33 & -128 & -94 \\
& 37 & 9 & 5.5 & 1.11 & -30 & & -98 \\
\hline
\end{tabular}

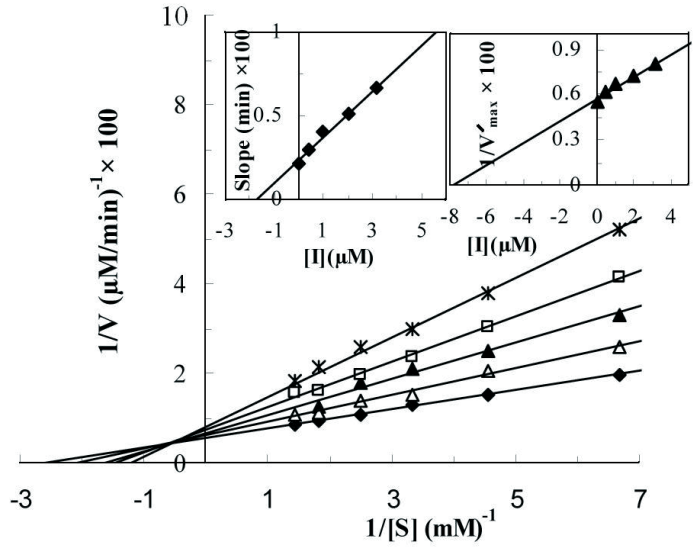

Figure 9. Lineweaver-Burk plots in the presence of fixed concentrations of II for catecholase activities; Insets: slope and 1/ $V_{\max }$ of Lineweaver-Burk plots versus inhibitor concentrations [II] L-DOPA was a substrate. The assay was done in $50 \mathrm{mM}$ sodium phosphate buffer, $\mathrm{pH} 6.8$, at $27^{\circ} \mathrm{C}$ and $6.52 \mu \mathrm{g} / \mathrm{ml}$ enzyme, in the presence of different concentrations of II: $0 \mu \mathrm{M}(\bullet), 0.4 \mu \mathrm{M}(\triangle)$, $1.0 \mu \mathrm{M}(\mathbf{\Delta}), 2.0 \mu \mathrm{M}(\square), 3.2 \mu \mathrm{M}(*)$.

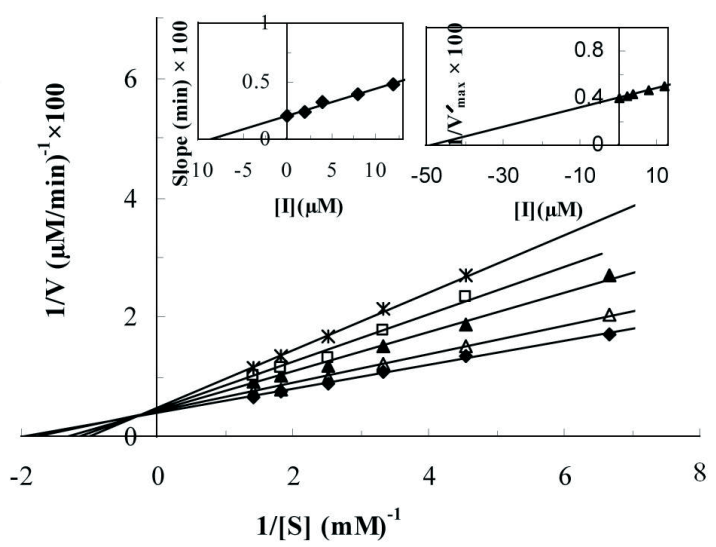

Figure 10. Lineweaver-Burk plots in the presence of fixed concentrations of II for catecholase activities; Insets: slope and 1/ $V_{\text {of }}$ of Lineweaver-Burk plots versus inhibitor concentrations [II] L-DOPA was a substrate. The assay was done in $50 \mathrm{mM}$ sodium phosphate buffer, $\mathrm{pH} 6.8$, at $37^{\circ} \mathrm{C}$ and $6.52 \mu \mathrm{g} / \mathrm{mL}$ enzyme, in the presence of different concentrations of II: $0 \mu \mathrm{M}(\bullet), 2.0 \mu \mathrm{M}(\triangle)$, $4.0 \mu \mathrm{M}(\mathbf{\Delta}), 8.0 \mu \mathrm{M}(\square), 12.0 \mu \mathrm{M}(*)$.

\section{Fluorescence study}

Intrinsic fluorescence of MT in the presence of $\mathbf{I}$ and II was measured in order to obtain additional information on the nature of their inhibitory effect on MT. Unexpectedly, addition of either of the two compounds to MT caused quenching of tryptophan emission (Fig. 11). It must be stressed that this quenching occurred without any change in the fluorescence band position. These observations suggest that no considerable conformational changes accompany binding of $\mathbf{I}$ 
(a)

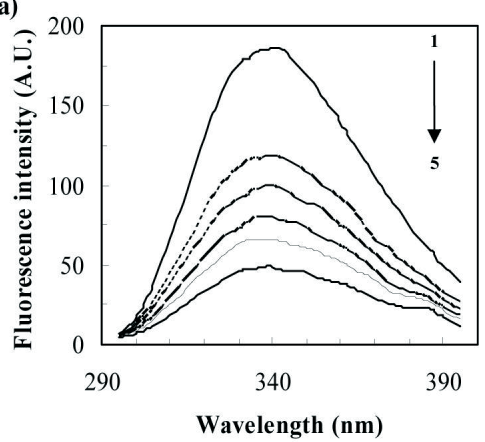

(b)

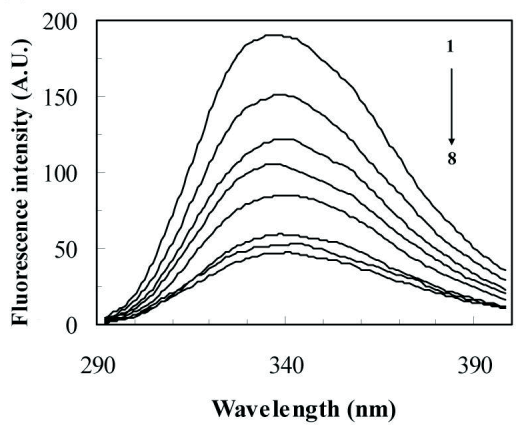

Figure 11. Intrinsic fluorescence changes of MT in the presence of different concentrations of (a) I and (b) II

The fluorescence emission spectra were measured in $50 \mathrm{mM}$ sodium phosphate buffer, $\mathrm{pH} 6.8$, at $27^{\circ} \mathrm{C}$ and $170 \mu \mathrm{g} / \mathrm{mL}$ enzyme, in the presence of different concentrations of I ( 1 to $5: 0,80,120$, $180,240,320 \mu \mathrm{M})$ and II (1 to $8: 0,0.2,0.4,0.8,1.2,2,2.5,3.2 \mu \mathrm{M})$. Wavelength of $280 \mathrm{~nm}$ was used to excite tryptophan residues of MT.

and II. Changes in extrinsic fluorescence of ANS upon its binding to MT in the presence of the two inhibitors were also monitored (Fig. 12). Only binding of I caused slight changes in ANS emission. This observation may indicate induction of minor changes in the tertiary structure of MT, incurred by hydrophobic interactions of the inhibitor with the enzyme.

\section{CONCLUSION}

The reported investigation documents effects of sodium salts of a monofunctional (I) and a bifunctional (II) dithiocarbamate on the activities and structure of mushroom tyrosinase. We hypothesize that the charged thiol heads of the dithiocarbamates play a direct role in the inhibition of tyrosinase by chelating the copper ions in its active site. Also, the phenolic group of $\mathbf{I}$ is suggested to interact with hydrophobic patches in the active site, thereby driving slight changes in the tertiary enzyme structure. It seems that these hydrophobic interactions decrease the inhibitory effects of the compound. On the other hand, the two charged heads of compound II interact electrostatically with the active site copper ions which diminishes its hydrophobic interaction. Compound II binds the active site of MT more strongly than I thereby decreasing the affinity of the substrate to the enzyme. This makes it an effective competitive inhibitor. Taking together, bifunctional dithiocarbamates, being strong chelaters of copper ions, are potent tyrosinase inhibitors.

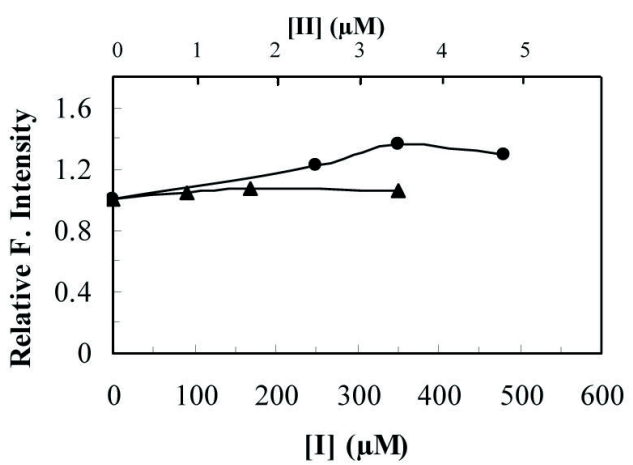

Figure 12. ANS-binding fluorescence spectra changes in the presence of various concentrations of I (lower axis: •) and II (upper axis: $\boldsymbol{\Delta}$ )

The fluorescence emission spectra were measured in $50 \mathrm{mM}$ sodium phosphate buffer, $\mathrm{pH} 6.8$, at $27^{\circ} \mathrm{C}$. Excitation wavelength of $385 \mathrm{~nm}$ was used to detect the ANS fluorescence. Molar concentration ratio (ANS /MT) is 50 .

\section{Acknowledgements}

The financial support given by the University of Tehran is gratefully acknowledged.

\section{REFERENCES}

Alijanianzadeh M, Saboury AA (2007) Temperature dependence of activation and inhibition of mushroom tyrosinase by ethyl xanthate. Bull Korean Chem Soc 28: 758-762.

Alijanianzadeh M, Saboury AA, Mansuri-Torshizi H, Haghbeen K, Moosavi-Movahedi AA (2007) The inhibitory effect of some new synthesized xanthates on mushroom tyrosinase activities. I Enzyme Inbib Med Chem 22: 239-246.

Amin E, Saboury AA, Mansoori-Torshizi H, Moosavi-Movahedi AA (2009) Potent inhibitory effects of benzyl and $p$-xylidine-bis dithiocarbamate sodium salts on activities of mushroom tyrosinase. $J$ Enzyme Inbib Med Chem (In press).

Artes F, Castaner M, Gil MI (1998) Review: Enzymatic browning in minimally processed fruit and vegetables. Food Sci Technol Int 4: 377-389.

Bittner S (2006) When quinones meet amino acids: chemical, physical and biological consequences. Amino Acids 30: 205-224.

Briganti S, Camera E, Picardo M (2003) Chemical and instrumental approaches to treat hyperpigmentation. Pigment Cell Res 16: 101-110.

Criton M, Mellay-Hamon VL (2008) Analogues of N-hydroxy- $N^{\prime}$-phenylthiourea and $N$-hydroxy- $N^{\prime}$-phenylurea as inhibitors of tyrosinase and melanin formation. Bioorg Med Chem Lett 18: 3607-3610.

Decker H, Schweikardt T, Tuczek F (2006) The first crystal structure of tyrosinase: All questions answered? Angew Chem Int Ed 45: 45464550.

Desai RM, Shah MK, Shah VH (2006) Preparation and antimicrobial screening of $\mathrm{Cu}(\mathrm{II}), \mathrm{Ni}(\mathrm{II}), \mathrm{Zn}(\mathrm{II})$ and $\mathrm{Cd}(\mathrm{II})$ complexes. Eur J Chem 3: 137-141.

Espin JC, Wichers HJ (2001) Effect of captopril on mushroom tyrosinase activity in vitro. Biochim Biophys Acta 1544: 289-300.

Fenoll LG, Rodriguez-Lopez JN, Garcia-Sevilla F, Garcia-Ruiz PA, Varon R, Garcia-Canovas F, Tudela J (2001) Analysis and interpretation of the action mechanism of mushroom tyrosinase on monophenols and diphenols generating highly unstable o-quinones. Biochim Biophys Acta 1548: 1-22.

Fraignier MP, Marques L, Fleuriet A, Macheix JJ (1995) Biochemical and immunochemical characteristics of polyphenol oxidases from different fruits of Prunus. I Agric Food Chem 43: 2375-2380.

Garcia-Molina F, Hiner AN, Fenoll LG, Rodriguez-Lopez JN, GarciaRuiz PA, Garcia-Canovas F, Tudela J (2005) Mushroom tyrosinase: catalase activity, inhibition, and suicide inactivation. J Agric Food Chem 53: 3702-3709.

García-Molina F, Muñoz JL, Varón R, Rodríguez-López JN, GarcíaCánovas F, Tudela J (2007) A review on spectrophotometric methods for measuring the monophenolase and diphenolase activities of tyrosinase. J Agric Food Chem 55: 9739-9749.

Gasymov OK, Glasgow BJ (2007) ANS fluorescence: potential to augment the identification of the external binding sites of proteins. Biochim Biophys Acta 1774: 403-411. 
Gheibi N, Saboury AA, Mansuri-Torshizi H, Haghbeen K, MoosaviMovahedi AA (2005) The inhibition effect of some $n$-alkyl dithiocarbamates on mushroom tyrosinase. J Enzyme Inbib Med Chem 20: 393-399.

Givseppina F, Sergio S, Diego M (2005) Pyrrolidine dithiocarbamates of Pd(II). Inorg Chim Acta 358: 971-980.

Halaouli S, Asther M, Sigoillot JC, Hamdi M, Lomascolo A (2006) Fungal tyrosinases: new prospects in molecular characteristics, bioengineering and biotechnological applications. I Appl Microbiol 100: 219-232.

Holm RH, Kennepohl P, Solomon EI (1996) Structural and functional aspects of metal sites in biology. Chem Rev 96: 2239-2314.

Jolley RL, Nelson RM (1969) The multiple forms of mushroom tyrosinase. structural studies on the isoenzymes. Biol Chem Hoppe-Seyler 244: 3251-3257.

Khwaja SS, Shahab AAN, Lutfullah C, Yonas C (2006) Template synthesis of symmetrical transition metal dithiocarbamates. J Bary Chem Soc 17: 107-112.

Kim YJ, Uyama H (2005) Tyrosinase inhibitors from natural and synthetic sources: structure, inhibition mechanism and perspective for the future. Cell Mol Life Sci 62: 1707-1723.

Lee KH, Koketsu M, Choi SY, Lee KJ, Lee P, Ishihara H, Kim SY (2005) Potent inhibitory effects of N-aryl S-alkylthiocarbamate derivatives on the Dopa oxidase activity of mushroom tyrosinase. Chem Pharm Bull (Tokyo) 53: 747-749.

Liu J, Cao R, Yi W, Ma C, Wan Y, Zhou B, Ma L, Song H (2009) A class of potent tyrosinase inhibitors: alkylidenethiosemicarbazide compounds. Eur I Med Chem 44: 1773-1778.

Manav N, Mishra AK, Kaushik NK (2006) In vitro antitumour and antibacterial studies of some Pt(IV) dithiocarbamate complexes. Spectrochim Acta Part A 65: 32-35.

Matoba Y, Kumagai T, Yamamoto A, Yoshitsu H, Sugiyama M (2006) Crystallographic evidence that the dinuclear copper center of tyrosinase is flexible during catalysis. J Biol Chem 281: 8981-8990.

Nakamura T, Sho S, Ogura Y (1966) On the purification and properties of mushroom tyrosinase. J Biochem 59: 481-486.

Park KH, Lee JR, Hahn HS, Kim YH, Bae CD, Yang JM, Oh S, Bae YJ, Kim DE, Hahn M-J (2006) Inhibitory effect of ammonium tetrathiotungstate on tyrosinase and its kinetic mechanism. Chem Pharm Bull (Tokyo) 54: 1266-1270.

Parvez S, Kang M, Chung HS, Cho C, Hong MC, Shin MK, Bae H (2006) Survey and mechanism of skin depigmenting and lightening agents. Phytother Res 20: 921-934.

Perozzo R, Folkers G, Scapozza L (2004) Thermodynamics of protein-ligand interactions: history, presence, and future aspects. $J R_{e}$ cept Signal Transduct 24: 1-52.

Rescigno A, Sollai F, Pisu B, Rinaldi A, Sanjust E (2002) Tyrosinase inhibition: General and applied aspects. J Ensyme Inbib Med Chem 17: 207-218.

Ronconi L, Maccato C, Barreca D, Saini R, Zancato MDF (2005) Gold (III) dithiocarbamate derivatives of N-methylglycine: an experimental and theoretical investigation. Polyhedron 24: 521-531.

Saboury AA, Alijanianzadeh M, Mansoori-Torshizi H (2007) The role of alkyl chain length in the inhibitory effect n-alkyl xanthates on mushroom tyrosinase activities. Acta Biochim Pol 54: 183-191.

Saboury AA (2009) Enzyme inhibition and activation: a general theory. J Iran Chem Soc 6: 219-229.

Saboury AA, Zolghadri S, Haghbeen K, Moosavi-Movahedi AA (2006) The inhibitory effect of benzenethiol on the cresolase and catecholase activities of mushroom tyrosinase. J Ensyme Inbib Med Chem 21: $711-717$.

Sanchez-Cortes S, Vasina M, Francioso O, Garcia-Ramos JV (1998) Raman and surface enhanced Raman spectroscopy of dithiocarbamate fungicides. Vib Spectrosc 17: 133-144.

Seo SY, Sharma VK, Sharma N (2003) Mushroom tyrosinase: recent prospects. I Agric Food Chem 51: 2837-2853.

Siddiqi KS, Sadaf K, Shahab AAN, El-ajaily MM (2007) Polynuclear transition metal complexes with thiocarbohydrazide and dithiocarbamates. Spectrochim Acta Part A 67: 995-1002.

Strothkamp KG, Jolley RL, Mason HS (1976) Quaternary structure of mushroom tyrosinase. Biochem Biophys Res Commun 70: 519-524.

Vaneet KS, Aulakh SJ, Malik AK (2005) Fourth derivative spectrophotometric determination of fungicide thiram (tetramethyldithiocarbamate) using sodium molybdate and its application. Talenta 65: 375-379. 